\title{
Local Ischemic Postconditioning during Primary Percutaneous Coronary Intervention: A Meta-Analysis
}

\author{
Yong Wei ${ }^{\mathrm{a}, \mathrm{b}}$ Lei Ruan ${ }^{\mathrm{c}}$ Genqing Zhou ${ }^{\mathrm{a}}$ Liqun Zhao ${ }^{\mathrm{a}}$ Baozhen $\mathrm{Qi}^{\mathrm{a}}$ \\ Ping Ouyang $^{b}$ Zhimin Jin $^{b}$ Cuntai Zhang ${ }^{c}$ Shaowen Liu ${ }^{a}$ \\ a Department of Cardiology, Shanghai First People's Hospital, School of Medicine, Shanghai Jiaotong University, and \\ ${ }^{b}$ Department of Cardiology, Shanghai Songjiang Center Hospital, Shanghai, and 'Department of Geratology, \\ Tongji Hospital, Tongji Medical College, Huazhong University of Science and Technology, Wuhan, China
}

For editorial comment see p. 223

\section{Key Words}

Acute myocardial infarction - Ischemic postconditioning •

Percutaneous coronary intervention

\begin{abstract}
Objectives: To investigate current evidence linking ischemic postconditioning (IPC) to cardioprotection in patients receiving primary percutaneous coronary intervention ( $\mathrm{PCl})$. Methods: We performed searches of PubMed, Embase, MEDLINE and Cochrane databases from January 1998 to May 2011 for identifying relevant studies comparing IPC with usual care in patients undergoing primary $\mathrm{PCl}$. A meta-analysis of eligible studies was assessed by Review Manager 5.0. Results: Thirteen studies were eligible. Compared to the control, observed outcomes such as peak creatine kinase [weighted mean difference (WMD) -537.48, 95\% confidence interval (Cl) -779.32 to $-295.65 \mathrm{IU} / \mathrm{I}]$, peak creatine kinasemyocardial band (WMD $-61.11,95 \% \mathrm{Cl}-76.56$ to $-45.66 \mathrm{U} / \mathrm{l}$ ), complete ST-segment resolution (risk ratio $1.38,95 \% \mathrm{Cl} 1.07$ to 1.77 ), blush grade during reflow (WMD $0.64,95 \% \mathrm{Cl} 0.49$ to 0.78 ), corrected TIMI frame count, single-photon emission computed tomography determining infarct size, long-term left ventricular ejection fraction and short-term and longterm wall motion score indexes were improved in IPC group,
\end{abstract}

with less occurrence of heart failure during the 3-month to 3.4-year follow-up. Conclusions: Though current evidence indicates that IPC provides potential cardioprotection to patients receiving primary $\mathrm{PCl}$, larger adequately powered studies should be undertaken to confirm its advantages.

Copyright $\odot 2012$ S. Karger AG, Basel

\section{Introduction}

Ischemic postconditioning (IPC) refers to several cycles of ischemia/reperfusion in the reperfusion treatment, followed by full restoration of coronary perfusion. Zhao et al. [1] first described the concept of IPC in 2003 and indicated it could reduce myocardial injury dramatically. Subsequent nonhuman investigations in vivo and in vitro confirmed such cardioprotective effects of IPC, i.e. significantly reducing infarct size, preventing reperfusion arrhythmias and improving cardiac function $[2$, 3]. During the emergency coronary intervention, IPC could be achieved by inflating and deflating the balloon alternately. Two years after the first animal experiment on IPC, 2 clinical trials were reported by Staat et al. [4] and Laskey [5]. These pilot studies demonstrated that IPC effectively reduced myocardial injury and improved

\section{KARGER}

Fax +4161306 1234 E-Mail karger@karger.ch www.karger.com

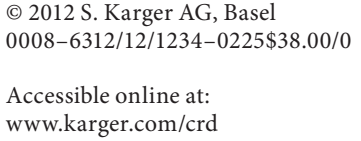

Shaowen Liu, PhD

Department of Cardiology, Shanghai First People's Hospital

Shanghai Jiaotong University School of Medicine

100 Haining Road, Hongkou District, Shanghai 200080 (China)

E-Mail shaowen.liu@yahoo.com 
prognosis in patients with acute myocardial infarction (AMI) receiving percutaneous coronary intervention (PCI). Clinical studies on IPC have gradually increased in recent years, but have been small, single center studies with inconsistent results. They have been proof-of-principle studies using surrogate end points to define a potential biological effect of IPC using (1) enzyme assessment of myocardial injury, (2) angiographic and invasive measures of coronary flow, (3) measures of left-ventricular function, (4) measures of infarct size and (5) adverse cardiac events during follow-up. We elected to perform a meta-analysis of these published data to ascertain whether IPC limits myocardial injury and improves prognosis in patients with AMI receiving PCI.

\section{Methods}

\section{Search Strategy}

Literature searches were performed to identify all relevant and published randomized, controlled, prospective studies comparing IPC and usual care in patients with AMI undergoing PCI. We searched electronic databases (PubMed, Embase, MEDLINE and Cochrane) from January 1998 to May 2011, using terms like 'postconditioning', 'acute myocardial infarction' and 'coronary intervention'. Our search was not restricted to articles in English. Hand research was also performed and the reference lists of all the retrieved articles were screened.

\section{Eligibility Criteria}

Criteria for inclusion were as follows: (1) a validated diagnosis of AMI, (2) a routine intervention in control group and IPC treatment during intervention in IPC group, without any differences in other treatments between the two, (3) a similar baseline between IPC and the control group, with a good match of age, gender, ischemic time and risk factors, (4) a randomized, controlled and prospective study, (5) the inclusion of one or more observed outcomes such as peak creatine kinase (CK), peak creatine kinasemyocardial band (CK-MB), complete ST-segment resolution (cSTR), perfusion defect index on single-photon emission computed tomography (PDI-SPECT), blush grade of perfusion, corrected TIMI frame count (CTFC), left ventricular ejection fraction (LVEF), wall motion score index (WMSI) and adverse cardiac events in the follow-up. Continuous variables were expressed as mean and standard deviation. Studies without any of the aboveobserved outcomes, a dissimilar baseline between the IPC and control groups or with confounding factors were excluded. Only the latest study was included in the meta-analysis for identical or largely similar articles.

\section{Study Selection and Quality Assessment}

Two investigators (Y.W. and L.R.) performed the literature search, study selection and data evaluation independently of one another. Disagreements were resolved by discussion or referred to a third investigator (C.Z.). Complete consensus among the authors on the final results was achieved. Studies included in the meta-analysis had to fulfill the eligibility criteria mentioned above. The main data information was extracted, including year of publication, article title, name of first author, published journal tile, study characteristics (random methods, grouping, baseline comparison and follow-up event) and observed outcomes. We adopted the criteria for study quality outlined by the Cochrane Reviewer's Handbook 4.2 for quality assessment of included randomized controlled trials. These criteria were as follows: (1) correct random methods, (2) concealment randomization, (3) blindness assessment, (4) the completeness of the follow-up and using ITT (intention to treat) analysis to deal with the dropouts. Based on the above criteria, studies were divided into 3 categories (A, B and $\mathrm{C}$ grades). We assigned the grade $\mathrm{A}$, suggesting minimal possible bias, if all 4 Cochrane criteria were met. We assigned the grade $\mathrm{B}$, considered to have a moderate probability of bias, if 1 or more were partially met; and if 1 or more were not met, it indicated a high probability of bias, so we assigned the grade C.

Statistics

We used the $\chi^{2}$ test to verify data heterogeneity between studies, with $p>0.05$ indicating data homogeneity. In order to test the overall effects, a fixed-effects model was used unless there was significant heterogeneity in the studies, which required a random-effects model [6]. For continuous variables, we used the weighted mean difference (WMD) as the study effect estimate. For discrete variables, we calculated the risk ratio (RR) with $95 \%$ confidence interval (CI) comparing the IPC group with the control group. A 2-tailed p value of $<0.05$ was considered significant. All statistical analysis was performed in statistical software (Review Manager 5.0).

\section{Results}

\section{Study Selection}

We identified 18 potentially relevant articles on IPC associated with PCI by scanning the titles and the abstracts. Five studies were excluded in the full text evaluation for the following reasons: 1 was possibly a duplicate [7], 1 was a retrospective chart review [8], 1 lacked any of our requisite outcomes [9], 1 was an ongoing study [10] and all the data of the 5 th study were presented as medians and 25th and 75th percentiles [11]. Finally, by screening the whole article, we selected 13 studies for meta-analysis. These eligible studies contained a total of 673 patients, with 352 in the IPC group and 321 in the control group. Two articles reported the same trial with the observation of different outcomes. The characteristics of the 13 studies included in the meta-analysis are summarized in table 1 . Table 2 notes the outcomes reported in each study.

\section{Study Quality}

The analysis of study quality in the 13 eligible studies is presented in table 3. Baselines between the IPC group and the control group in all the studies were comparable. 
Table 1. Characteristics of studies included in the meta-analysis

\begin{tabular}{|c|c|c|c|c|c|c|c|c|}
\hline \multirow[t]{2}{*}{ Study (first author) } & \multirow[t]{2}{*}{ Total IPC/Con } & \multirow{2}{*}{$\begin{array}{l}\text { Age, years } \\
\text { IPC/Con }\end{array}$} & \multirow{2}{*}{$\begin{array}{l}\text { Ischemia } \\
\text { time, min } \\
\text { IPC/Con }\end{array}$} & \multirow{2}{*}{$\begin{array}{l}\text { Post-con- } \\
\text { ditioning } \\
\text { protocol }\end{array}$} & \multicolumn{3}{|c|}{ Culprit artery (IPC/Con) } & \multirow{2}{*}{$\begin{array}{l}\text { TIMI grade }(0 / 1 / 2) \\
\text { before PCI (IPC/ } \\
\text { Con) }\end{array}$} \\
\hline & & & & & LAD & LCX & RCA & \\
\hline Staat 2005 [4] & $16(12) / 14(13)$ & $58 / 56$ & $331 / 318$ & $60 \mathrm{~s} \times 4$ & $6 / 6$ & - & $10 / 8$ & $(16 / 0 / 0) /(14 / 0 / 0)$ \\
\hline Laskey 2005 [5] & $10(5) / 7(5)$ & $58 / 58$ & $341 / 286$ & $90 s \times 2$ & $5 / 4$ & $1 / 1$ & $4 / 2$ & - \\
\hline $\mathrm{Ma} 2006$ [7] & $47(31) / 47(33)$ & $64 / 64$ & - & $30 \mathrm{~s} \times 3$ & $23 / 25$ & $11 / 8$ & $13 / 14$ & $(30 / 12 / 5) /(33 / 10 / 4)$ \\
\hline Ma 2007 [12] & $32(21) / 29(20)$ & $64 / 64$ & $396 / 426$ & $30 s \times 3$ & $17 / 15$ & $7 / 5$ & $8 / 9$ & $(21 / 8 / 3) /(20 / 6 / 3)$ \\
\hline Yang 2007 [13] & $23(20) / 18(11)$ & $59 / 63$ & $312 / 264$ & $30 \mathrm{~s} \times 3$ & $15 / 11$ & $2 / 1$ & $6 / 6$ & $(23 / 0 / 0) /(18 / 0 / 0)$ \\
\hline Thibault 2008 [14] & $17(13) / 21(16)$ & $56 / 56$ & $283 / 297$ & $60 s \times 4$ & $9 / 11$ & - & $8 / 10$ & $(17 / 0 / 0) /(21 / 0 / 0)$ \\
\hline Laskey 2008 [15] & $12(7) / 12(7)$ & $60 / 58$ & $228 / 222$ & $90 \mathrm{~s} \times 2$ & $12 / 12$ & - & - & $(9 / 3 / 0) /(8 / 4 / 0)$ \\
\hline Lønborg $2010^{1}[16,17]$ & $59(45) / 59(47)$ & $61 / 62$ & $241 / 255$ & $30 \mathrm{~s} \times 4$ & $26 / 23$ & $5 / 11$ & $28 / 25$ & $(59 / 0 / 0) /(59 / 0 / 0)$ \\
\hline Xue 2010 [18] & $23(22) / 20(19)$ & $54 / 62$ & $246 / 324$ & $60 \mathrm{~s} \times 4$ & $10 / 12$ & - & $13 / 8$ & $(23 / 0 / 0) /(20 / 0 / 0)$ \\
\hline \multirow[t]{2}{*}{$\operatorname{Lin} 2010^{2}[19]$} & $25(21)$ & 59 & - & $30 \mathrm{~s} \times 3$ & 16 & 2 & 7 & $(25 / 0 / 0)$ \\
\hline & $24(17) / 26(17)$ & $58 / 63$ & & $60 s \times 3$ & $13 / 16$ & $2 / 2$ & $9 / 8$ & $(24 / 0 / 0) /(26 / 0 / 0)$ \\
\hline Garcia 2011 [20] & $22(19) / 21(16)$ & $61 / 55$ & - & $30 s \times 4$ & $8 / 5$ & $5 / 2$ & $9 / 14$ & $(22 / 0 / 0) /(21 / 0 / 0)$ \\
\hline Liu 2011 [21] & $30(22) / 34(23)$ & $59 / 59$ & $310 / 324$ & $30 s \times 3$ & $16 / 20$ & $3 / 4$ & $11 / 10$ & $(30 / 0 / 0) /(34 / 0 / 0)$ \\
\hline
\end{tabular}

Con = Control; LAD = left anterior descending artery; LCX = left circumflex; RCA = right coronary artery.

${ }^{1}$ Lønborg et al. published 2 articles on the same trial, observing different outcomes.

${ }^{2}$ Lin et al. compared 60 -second postconditioning with 30 -second postconditioning and no postconditioning (routine) in this study.

Table 2. Summary of outcomes in the 13 prospective studies included in the meta-analysis

\begin{tabular}{|c|c|c|c|c|c|c|c|c|c|}
\hline Study (first author) & $\begin{array}{l}\text { Peak } \\
\text { CK }\end{array}$ & $\begin{array}{l}\text { Peak } \\
\text { CK-MB }\end{array}$ & STR & $\begin{array}{l}\text { PDI- } \\
\text { SPECT }\end{array}$ & $\begin{array}{l}\text { Blush } \\
\text { grade }\end{array}$ & CTFC & LVEF & WMSI & $\begin{array}{l}\text { Follow-up } \\
\text { events }\end{array}$ \\
\hline Staat $2005[4]$ & $*$ & & & & * & & & & \\
\hline Laskey 2005 [5] & $*$ & & & & & & & & \\
\hline Ma 2006 [7] & * & * & & & & $*$ & & * & \\
\hline Ma 2007 [12] & $*$ & $*$ & & & & $*$ & & * & \\
\hline Yang 2007 [13] & $*$ & & * & $*$ & * & & $*$ & & \\
\hline Thibault 2008 [14] & & & & * & & & * & * & \\
\hline Laskey 2008 [15] & * & & & & & & * & & \\
\hline Lønborg 2010 [16] & & & * & & & & & & 15 month $^{*}$ \\
\hline Lønborg 2010 [17] & & & & & & & * & & 3 month* \\
\hline Xue 2010 [18] & & * & * & * & & & * & * & \\
\hline Lin 2010 [19] & & & & & & & * & * & \\
\hline Garcia 2011 [20] & * & * & & & & & $*$ & * & 3.4 year* \\
\hline Liu $2011[21]$ & * & * & & & * & * & * & * & \\
\hline
\end{tabular}

STR $=$ ST-segment resolution

* Indicated outcomes described in relative studies. Lønborg et al. wrote 2 articles reporting the same trial but observing different outcomes.

Measurement data was compared by Student's $t$ test and count data was compared by $\chi^{2}$ test between the 2 groups. If details pertaining to randomization, blinding, dropouts and withdraws were not specified in the original articles, the chief investigator (Y.W.) was responsible for getting clarification from the primary author by e-mail or telephone. In terms of quality, each of these studies would be graded level B according to the Cochrane Reviewer's Handbook 4.2 for quality assessment of included randomized controlled trials. 


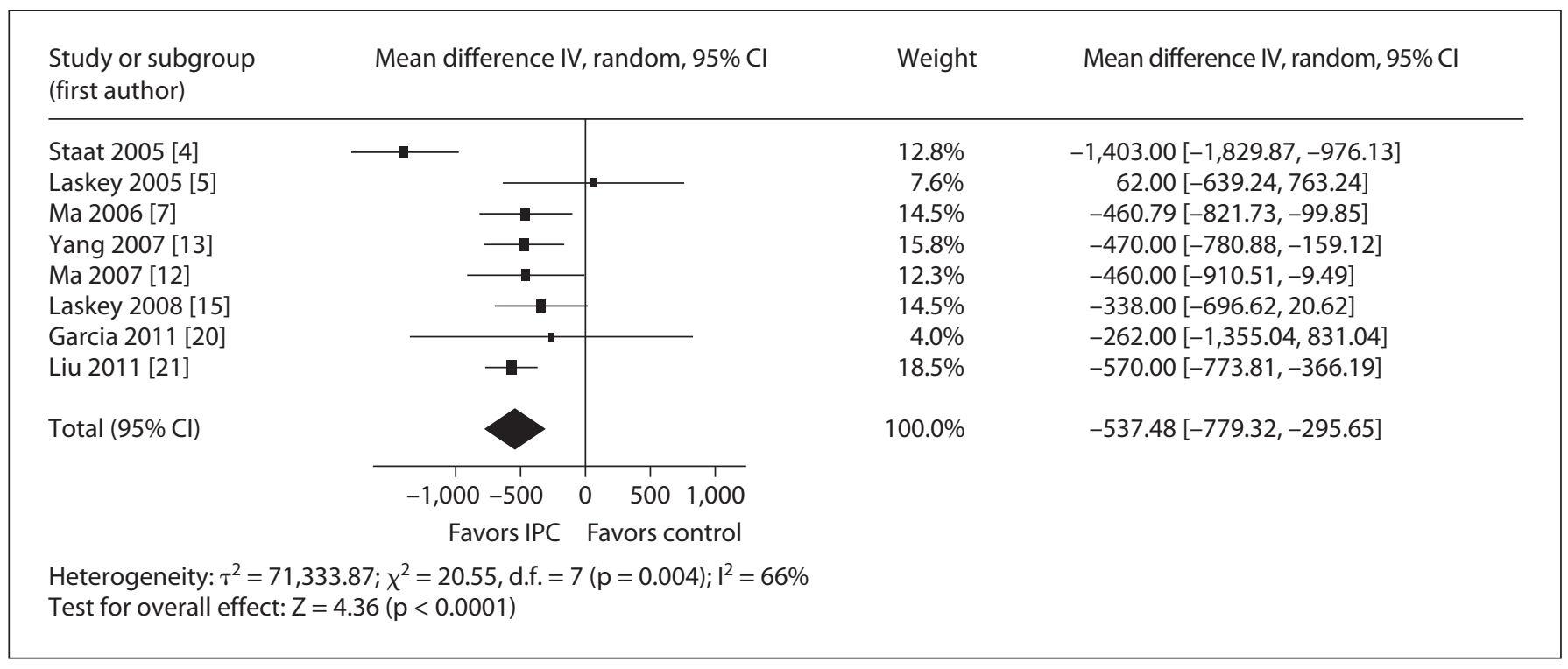

Fig. 1. A meta-analysis of 8 eligible studies on peak CK.

Table 3. Quality assessments of studies included in the meta-analysis

\begin{tabular}{|c|c|c|c|c|c|}
\hline Study (first author) & $\begin{array}{l}\text { Technique of } \\
\text { randomization }\end{array}$ & $\begin{array}{l}\text { Concealed } \\
\text { randomizetion }\end{array}$ & $\begin{array}{l}\text { Blinded } \\
\text { assessment }\end{array}$ & $\begin{array}{l}\text { Dropout } \\
\text { rate }\end{array}$ & $\begin{array}{l}\text { Similar } \\
\text { baseline }\end{array}$ \\
\hline Staat 2005 [4] & Yes & Yes & Yes & Unclear & Yes \\
\hline Laskey 2005 [5] & Yes & Yes & Unclear & Unclear & Yes \\
\hline $\mathrm{Ma} 2006$ [7] & Yes & Unclear & Unclear & Unclear & Yes \\
\hline Ma 2007 [12] & Yes & Yes & Unclear & Unclear & Yes \\
\hline Yang 2007 [13] & Yes & Yes & Unclear & Unclear & Yes \\
\hline Thibault 2008 [14] & Yes & Yes & Yes & 0 & Yes \\
\hline Laskey 2008 [15] & Yes & Yes & Yes & Unclear & Yes \\
\hline Lønborg $2010^{1}[16,17]$ & Yes & Yes & Yes & 0 & Yes \\
\hline Xue 2010 [18] & Yes & Yes & Yes & Unclear & Yes \\
\hline Lin $2010^{2}[19]$ & Yes & Yes & Unclear & Unclear & Yes \\
\hline Garcia 2011 [20] & Yes & Unclear & Unclear & 0.12 & Yes \\
\hline Liu $2011[21]$ & Yes & Yes & Unclear & Unclear & Yes \\
\hline
\end{tabular}

${ }^{1}$ Lønborg et al. published 2 articles on the same trial but observing different outcomes.

${ }^{2}$ Lin et al. compared 60 -second postconditioning with 30 -second postconditioning and no postconditioning (routine) in this study.

Biochemical Markers of Acute Myocardial Infarction

The commonly used biochemical markers of AMI are $\mathrm{CK}$ and $\mathrm{CK}-\mathrm{MB}$, which are associated with infarct size. Eight studies compared the impact of IPC with the control (i.e. no IPC) on the peak of serum myocardial enzyme concentration after acute infarction. Four of these studies indicated that IPC reduced the peak CK after myocardial infarction, while the others indicated oppos- ing results. Our meta-analysis of these studies suggested that IPC significantly decreased peak CK after myocardial infarction (WMD -537.48, 95\% CI -779.32 to -295.65 IU/liter, $\mathrm{p}<0.0001$ ) (fig. 1). Similarly, IPC also significantly decreased peak CK-MB (WMD -61.11, 95\% CI -76.56 to -45.66 IU/liter, $p<0.00001$ ) (fig. 2). Therefore, it was showed that IPC can reduce ischemic necrosis of myocardium after acute infarction. 


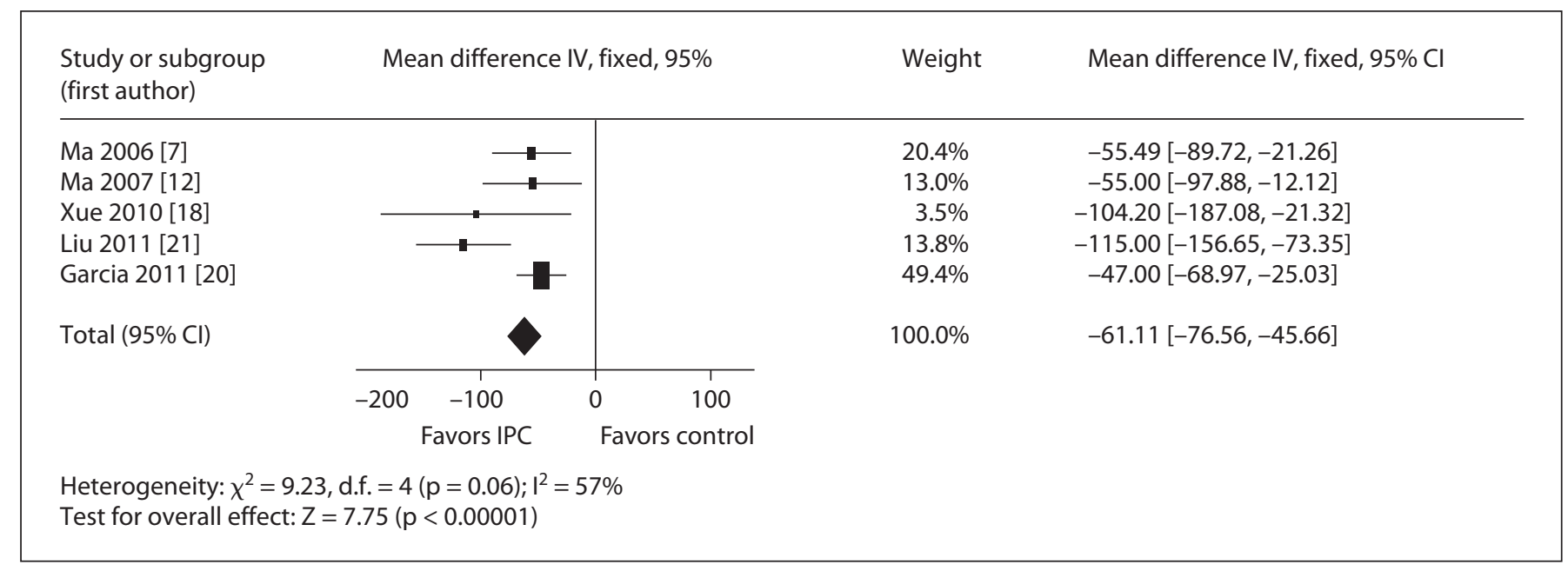

Fig. 2. A meta-analysis of 5 eligible studies on peak CK-MB.

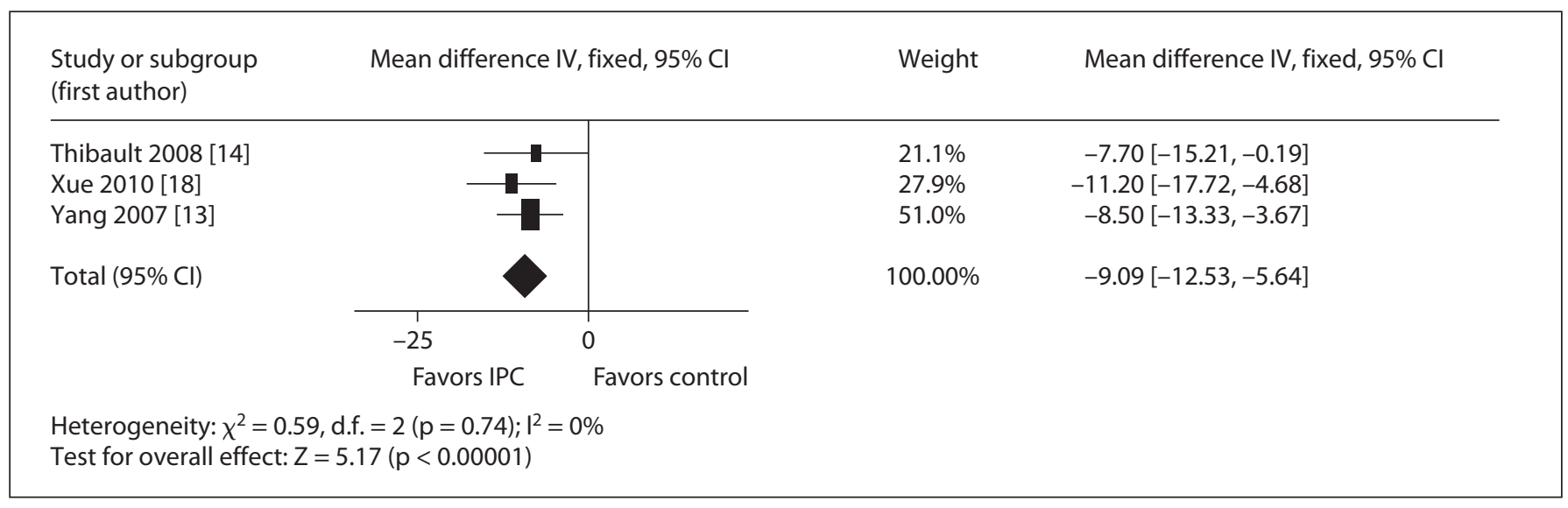

Fig. 3. A meta-analysis of 3 eligible studies on SPECT determining infarct size.

\section{Myocardial Infarct Size Measured by Imaging}

There were 3 studies describing the outcome of SPECT infarct size (fig. 3). The meta-analysis of these studies demonstrated that the perfusion defect index on SPECT, an estimate of infarct size, was significantly reduced in the IPC group versus the control group, with a WMD of $-9.09 \%$ (95\% CI -12.53 to $-5.64, \mathrm{p}<0.00001)$.

\section{Markers of Reperfusion}

Reperfusion outcomes following IPC were described by cSTR, blush grade during reflow and CTFC in the eligible studies. Figure 4 shows data on the outcome of cSTR. Three trials were included in the meta-analysis, with 2 suggesting no improvement in CSTR for IPC pretreatment. The pooled estimate of RR from all 3 trials was statistically significant (RR $1.38,95 \%$ CI 1.07 to $1.77, \mathrm{p}=$ 0.01). The blush grade, a marker of myocardial perfusion, was significantly higher in the hearts of the IPC group than in those of the controls, with a WMD (IPC vs. control) of 0.64 (95\% CI 0.49 to $0.78, \mathrm{p}<0.00001)$ (table 4). CTFC was also used to evaluate the velocity of coronary flow after PCI. Patients of the IPC group had faster CTFC than patients of the control group, with a WMD (IPC vs. control) of -4.33 (95\% CI -5.61 to $-3.05, \mathrm{p}<0.00001)$ (table 4).

\section{Cardiac Function Measures}

Table 5 presents data on the outcomes of LVEF and WMSI in patients with AMI undergoing primary PCI. There are some differences in the methods used to assess 
Table 4. A meta-analysis for reperfusion outcomes after primary PCI

\begin{tabular}{|c|c|c|c|c|c|}
\hline \multirow{2}{*}{$\begin{array}{l}\text { Outcomes of } \\
\text { reperfusion }\end{array}$} & \multirow{2}{*}{$\begin{array}{l}\text { Contributing } \\
\text { studies (references) }\end{array}$} & \multirow{2}{*}{$\begin{array}{l}\text { Sample size } \\
\text { (IPC/control) }\end{array}$} & \multicolumn{3}{|c|}{ Treatment effect } \\
\hline & & & WMD & $95 \% \mathrm{CI}$ & $\mathrm{p}$ value \\
\hline Blush grade & {$[4,13,21]$} & $69 / 66$ & 0.64 & 0.49 to 0.78 & $<0.00001$ \\
\hline CTFC & {$[7,12,21]$} & $109 / 110$ & -4.33 & -5.61 to -3.05 & $<0.00001$ \\
\hline
\end{tabular}

Table 5. Impact of IPC on LVEF and WMSI in the short and long term

\begin{tabular}{|c|c|c|c|c|c|}
\hline \multirow[t]{2}{*}{ Outcomes of LV function } & \multirow{2}{*}{$\begin{array}{l}\text { Contributing } \\
\text { studies (references) }\end{array}$} & \multirow{2}{*}{$\begin{array}{l}\text { Sample size } \\
\text { (IPC/control) }\end{array}$} & \multicolumn{3}{|c|}{ Treatment effect } \\
\hline & & & WMD & $95 \% \mathrm{CI}$ & $\mathrm{p}$ value \\
\hline LVEF, within 7 days & {$[13,15,18-21]$} & $159 / 157$ & 0.18 & -0.75 to 1.10 & 0.71 \\
\hline LVEF, over 3 months & {$[14,17,19,20]$} & $131 / 137$ & 7.79 & 7.12 to 8.46 & $<0.00001$ \\
\hline WMSI, within 7 days & {$[18,20,21]$} & $102 / 106$ & -0.45 & -0.48 to -0.42 & $<0.00001$ \\
\hline WMSI, over 3 months & {$[7,12,14,19]$} & $109 / 110$ & -0.33 & -0.36 to -0.31 & $<0.00001$ \\
\hline
\end{tabular}

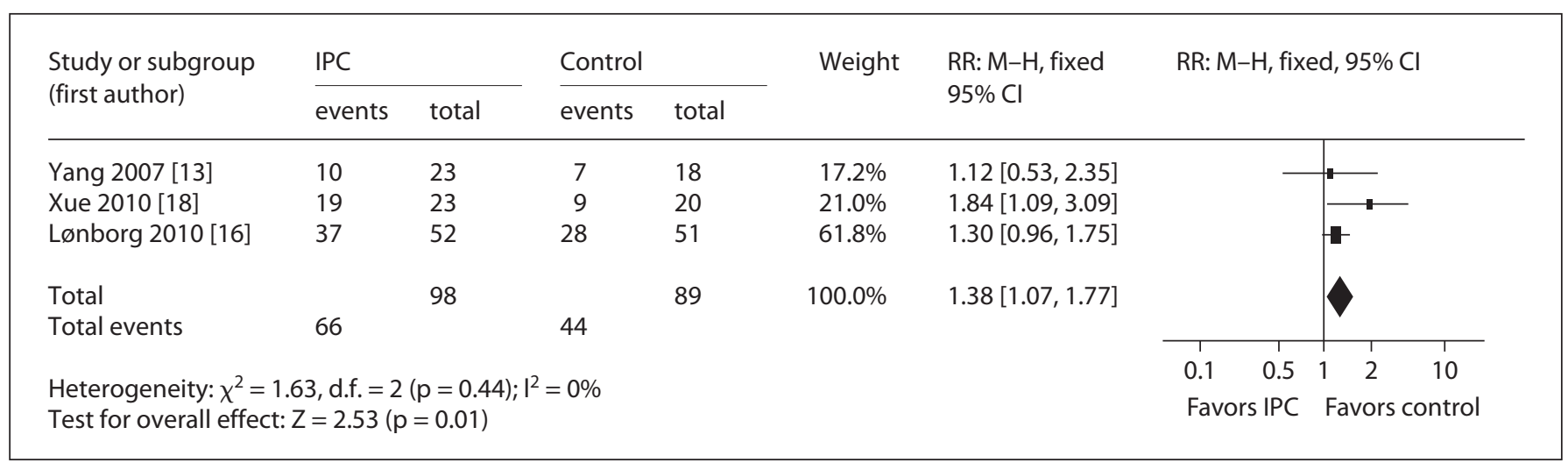

Fig. 4. A meta-analysis of 3 eligible studies on cSTR.

LVEF, with 6 studies using echocardiography $[13-15,18$, 19, 21], 1 using MRI [17], and 1 using echocardiography or MRI for each group, respectively [20]. LVEF was comparable between the IPC group and the control group in the short term within 7 days after PCI (WMD 0.18, 95\% CI -0.75 to $1.10, \mathrm{p}=0.71$ ). But in the long term over 3 months, LVEF was significantly more improved in the IPC group than in the control group (WMD 7.79, 95\% CI 7.12 to $8.46, \mathrm{p}<0.00001)$. Patients undergoing IPC had a lower WMSI (a value of 1 is normal segmental motion and higher values indicate poorer contraction) than those who received usual primary PCI in both the short term within 7 days (WMD $-0.45,95 \%$ CI -0.48 to -0.42 , $\mathrm{p}<$ 0.00001 ) and the long term over 3 months (WMD -0.33 , $95 \%$ CI -0.36 to $-0.31, \mathrm{p}<0.00001)$.

\section{Cardiac Events during Follow-Up}

Only 3 studies reported adverse cardiac events occurring during follow-up, including death, reinfarction, heart failure (NYHA 2-4), angina (CCS 1-4) and stent thrombosis. The long-term benefit of IPC was indicated in our meta-analysis. Table 6 presents data on the outcomes of adverse cardiac events in a follow-up of 3 months to 3.4 years. IPC reduced heart failure significantly more 
Table 6. Meta-analysis on the long-term follow-up outcomes of the included trials

\begin{tabular}{|c|c|c|c|c|c|}
\hline \multirow{2}{*}{$\begin{array}{l}\text { Outcomes of adverse } \\
\text { cardiac events in follow-up }\end{array}$} & \multirow{2}{*}{$\begin{array}{l}\text { Contributing } \\
\text { studies (references) }\end{array}$} & \multirow{2}{*}{$\begin{array}{l}\text { Sample size } \\
\text { IPC/control }\end{array}$} & \multicolumn{3}{|l|}{$\mathrm{RR}$} \\
\hline & & & $\mathrm{M}-\mathrm{H}$ & $95 \% \mathrm{CI}$ & $\mathrm{p}$ value \\
\hline Heart failure (NYHA 2-4) & {$[16,17,20]$} & $136 / 136$ & 0.55 & 0.37 to 0.83 & 0.004 \\
\hline Death & {$[16,17,20]$} & $136 / 136$ & 3.49 & 0.74 to 16.49 & 0.11 \\
\hline Angina (CCS 1-4) & {$[16,17]$} & $114 / 115$ & 1.41 & 0.65 to 3.05 & 0.38 \\
\hline Reinfarction & {$[16,17]$} & $114 / 115$ & 3.53 & 0.75 to 16.64 & 0.11 \\
\hline Stent thrombosis & {$[16,17]$} & $114 / 115$ & 0.43 & 0.06 to 2.89 & 0.39 \\
\hline
\end{tabular}

than the usual treatment (RR $0.55,95 \%$ CI 0.37 to 0.83 , $\mathrm{p}=0.004)$, but no significant differences were in death, angina, reinfarction and stent thrombosis were observed (table 6).

\section{Discussion}

AMI is a major cause of death and heart failure in both high- and low-income countries [22]. Recent studies have confirmed that rapid reperfusion is critical to rescue the ischemic myocardium. However, reperfusion has the potential to cause secondary injury to the myocardium, including myocardial stunning, no reflow and ventricular arrhythmias [23-25]. Ischemic preconditioning was first introduced as a powerful strategy to attenuate reperfusion injury [26], but it obviously had limited utility in clinical practice as it required an intervention before a patient experienced symptomatic cardiac ischemia or infarction. However, unlike ischemic preconditioning, IPC performed during angioplasty is technically simple and safe, for cycles of 'ischemia/reperfusion' can be easily achieved by repeatedly deflating and inflating the balloon in the culprit artery. The underlying mechanism of cardioprotection was initially attributed to the reduction of oxidative stress, decreasing intracellular calcium overload, improving endothelial function and depressing inflammation like ischemic preconditioning [4]. Further observations underlying the cardioprotective effects of IPC have been well studied in different animal models [27-31] and reviewed in multiple reviews [32-34].

The clinical applicability and simple technique of IPC permitted it to be readily assimilated into angioplasty interventions for acute ischemia. In 2005, Staat et al. [4] demonstrated that IPC by angioplasty could reduce infarct size by $36 \%$, assessed by early CK release in the human heart. This study indicated the feasibility and cardioprotection of IPC in the human heart for the first time. Multiple subsequent clinical trials have confirmed positive outcomes associated with IPC [7, 13, 18-21], but small sample size and less positive outcomes in other studies called for a meta-analytic approach. Our metaanalysis indicated that IPC caused a reduction of about 500 IU in peak CK after AMI, showing that IPC can reduce ischemic necrosis of myocardium after acute infarction. Other beneficial effects of IPC in the human heart were also observed, such as reducing SPECT-determined myocardial infarct size, and improving reperfusion outcomes, cardiac function and prognosis. Moreover, IPC did not improve LVEF within 7 days, but did improve it significantly over 3 months. Thibault et al. [14] demonstrated that myocardial stunning might mask any beneficial effect of contractile function within days to weeks after AMI, but no longer interfered with the effects of IPC in improving the recovery of regional contractile function after several months. The meta-analysis by Hansen et al. [35] did not analyze the long-term benefit of IPC because the studies observing follow-up outcomes to determine IPC's long-term benefit were performed after their meta-analysis. We presented data on outcomes of adverse cardiac events in a follow-up of 3 months to 3.4 years, which showed that IPC significantly reduced heart failure, but no significant differences were observed in death, angina, reinfarction and stent thrombosis. These revealed that IPC could improve cardiac function by reducing reperfusion-induced myocardial injury and infarct size. Clearly, here there are statistical differences to support use of this technique in routine practice.

The ongoing trial POSTEMI (Postconditioning in STElevation Myocardial Infarction) is a prospective, randomized control study, which selected 260 patients. The purpose was to evaluate the impact of IPC on the final myocardial infarct size in patients with ST-segment elevation myocardial infarction [10]. We look forward to 
seeing whether our meta-analytic findings are confirmed by POSTEMI, and, regardless of these findings, clearly a number of technical questions about IPC have still to be clarified. Though a lot of studies on IPC in animal models or humans have been well performed, we still feel puzzled by many questions. For example, 'What is the most efficient, simplest and safest postconditioning procedure for human hearts?' The postconditioning protocols in recent studies included $30 \mathrm{~s} \times 3,30 \mathrm{~s} \times 4,60 \mathrm{~s} \times 3,60 \mathrm{~s}$ $\times 4$, and $90 \mathrm{~s} \times 3$ and the most popular protocol was $30 \mathrm{~s} \times 3$ (table 1). One may question whether different protocols have different cardioprotective effects. However, only 1 study tested the hypothesis that postconditioning of $60 \mathrm{~s} \times 3$ was more efficient than postconditioning of $30 s \times 3$ [19]. Therefore, additional trials of a large scale are needed to address the time window for triggering postconditioning in patients undergoing PCI.

\section{Conclusion}

IPC has a potent protective effect on the ischemic heart. These virtues (ease of use and benefit) make it worthy of consideration in a selected group of patients with ST-elevation myocardial infarction.

\section{Acknowledgement}

We gratefully acknowledge the generous assistance from the Doctoral Students Innovation Fund of Shanghai Jiao Tong University School of Medicine (BXJ201135).

\section{References}

1 Zhao ZQ, Corvera JS, Halkos ME, Kerendi F, Wang NP, Guyton RA, Vinten-Johansen J: Inhibition of myocardial injury by ischemic postconditioning during reperfusion: comparison with ischemic preconditioning. Am J Physiol Heart Circ Physiol 2003;285:H579H588.

- 2 Ma X, Zhang X, Li C, Luo M: Effect of postconditioning on coronary blood flow velocity and endothelial function and LV recovery after myocardial infarction. J Intervent Cardiol 2006; 19:367-375.

-3 Dow J, Kloner RA: Postconditioning does not reduce myocardial infarct size in an in vivo regional ischemia rodent model. J Cardiovasc Pharmacol Ther 2007;12:153-163

-4 Staat P, Rioufol G, Piot C, Cottin Y, Cung TT, L'Huillier I, Aupetit JF, Bonnefoy E, Finet G, André-Fouët X, Ovize M: Postconditioning the human heart. Circulation 2005;112: 2143-2148.

5 Laskey WK: Brief repetitive balloon occlusions enhance reperfusion during percutaneous coronary intervention for acute myocardial infarction: a pilot study. Catheter Cardiovasc Interv 2005;65:361-367.

6 Petitti DB: 2000. Statistical methods in meta-analysis; in: Metaanalysis, Decision Analysis, and Cost-Effectiveness Analysis, ed 2. New York, Oxford University Press, pp 94118.

7 Ma XJ, Zhang XH, Li CM, Luo M: Effect of postconditioning on coronary blood flow velocity and endothelial function in patients with acute myocardial infarction. Scand Cardiovasc J 2006;40:327-333
8 Darling CE, Solari PB, Smith CS, Furman MI, Przyklenk K: 'Postconditioning' the human heart: multiple balloon inflations during primary angioplasty may confer cardioprotection. Basic Res Cardiol 2007;102:274278.

-9 Zhao WS, Xu L, Wang LF, Zhang L, Zhang ZY, Liu Y, Liu XL, Yang XC, Cui L, Zhang L: A 60 -s postconditioning protocol by percutaneous coronary intervention inhibits myocardial apoptosis in patients with acute myocardial infarction. Apoptosis 2009;14:12041211.

10 Limalanathan S, Andersen GØ, Hoffmann P, Kløw NE, Abdelnoor M, Eritsland J: Rationale and design of the POSTEM (Postconditioning in ST-Elevation Myocardial Infarction) study. Cardiology 2010;116:103-109.

11 Sörensson P, Saleh N, Bouvier F, Böhm F, Settergren M, Caidahl K, Tornvall P, Arheden H, Rydén L, Pernow J: Effect of postconditioning on infarct size in patients with ST elevation myocardial infarction. Heart 2010;96:1710-1715.

12 Ma XJ, Zhang XH, Luo M, Li CM, Shao JH: Effects of preconditioning and postconditioning on emergency percutaneous coronary intervention in patients with acute myocardial infarction. Natl Med J China 2007;87:114-117.

13 Yang XC, Liu Y, Wang LF, Cui L, Wang T, Ge YG, Wang HS, Li WM, Xu L, Ni ZH, Liu SH, Zhang L, Jia HM, Vinten-Johansen J, Zhao ZQ: Reduction in myocardial infarct size by postconditioning in patients after percutaneous coronary intervention. J Invasive Cardiol 2007; 19:424-430.
${ }_{14}$ Thibault H, Piot C, Staat P, Bontemps L, Sportouch C, Rioufol G, Cung TT, Bonnefoy E, Angoulvant D, Aupetit JF, Finet G, AndréFouët X, Macia JC, Raczka F, Rossi R, Itti R, Kirkorian G, Derumeaux G, Ovize M: Longterm benefit of postconditioning. Circulation 2008;117:1037-1044.

15 Laskey WK, Yoon S, Calzada N, Ricciardi MJ: Concordant improvements in coronary flow reserve and ST-segment resolution during percutaneous coronary intervention for acute myocardial infarction: a benefit of postconditioning. Catheter Cardiovasc Interv 2008; $72: 212-220$.

-16 Lønborg J, Holmvang L, Kelbæk H, Vejlstrup N, Jørgensen E, Helqvist S, Saunamäki K, Clemmensen P, Treiman M, Jensen JS, Engstrøm T: ST-segment resolution and clinical outcome with ischemic postconditioning and comparison to magnetic resonance. Am Heart J 2010;160:1085-1091.

17 Lønborg J, Kelbaek H, Vejlstrup N, Jørgensen E, Helqvist S, Saunamäki K, Clemmensen P, Holmvang L, Treiman M, Jensen JS, Engstrøm T: Cardioprotective effects of ischemic postconditioning in patients treated with primary precutaneous coronary intervention, evaluated by magnetic resonance. Circ Cardiovas Interv 2010;3:34-41.

18 Xue F, Yang X, Zhang B, Zhao C, Song J, Jiang T, Jiang W: Postconditioning the human heart in percutaneous coronary intervention. Clin Cardiol 2010;33:439-444. 
19 Lin X, Zhang ZY, Wang LF, Zhang L, Liu Y, Liu XL, Yang XC, Cui L, Zhang L: Attenuation of tumor necrosis factor- $\alpha$ elevation and improved heart function by postconditioning for 60 seconds in patients with acute myocardial infarction. Chin Med J 2010;123: 1833-1839.

-20 Garcia S, Henry TD, Wang YL, Chavez IJ, Pedersen WR, Lesser JR, Shroff GR, Moore L, Traverse JH: Long-term follow-up of patients undergoing postconditioning during ST-elevation myocardial infarction. J Cardiovasc Transl Res 2011;4:92-98.

21 Liu T, Mishra AK, Ding F: Protective effect of ischemic postconditioning on reperfusion injury in patients with ST-segment elevation acute myocardial infarction. Chin J Cardiol 2011;39:35-39.

22 Mathers CD, Loncar D: Projections of global mortality and burden of disease from 2002 to 2030. PLoS Med 2006;3:2011-2030.

-23 Kloner RA, Jennings RB: Consequences of brief ischemia: stunning, preconditioning, and their clinical implications. Part 2. Circulation 2001;104:3158-3167.
24 Hausenloy DJ, Yellon DM: Preconditioning and postconditioning: new strategies for cardioprotection. Diabetes Obes Metab 2008; 10:451-459.

25 Piper HM, Meuter K, Schafer C: Cellular mechanisms of ischemia-reperfusion injury. Ann Thorac Surg 2003;75:S644-S648.

26 Murry CE, Jennings RB, Reimer KA: Preconditioning with ischemia: a delay of lethal cell injury in ischemic myocardium. Circulation 1986;74:1124-1136.

27 Mykytenko Kerendi F, Reeves JG, Kin H, Zatta AJ, Jiang R, Guyton RA, Vinten-Johansen J, Zhao ZQ: Long-term inhibition of myocardial infarction by postconditioning during reperfusion. Basic Res Cardiol 2007; 102:90-100.

28 Argaud L, Gateau-Roesch O, Raisky O, Loufouat J, Robert D, Ovize M: Postconditioning inhibits mitochondrial permeability transition. Circulation 2005;111:194-197.

29 Skyschally A, Gres P, Van Caster P, Schulz R, Heusch G: Postconditioning reduces infarct size after ischemia/reperfusion in pigs. J Molec Cell Cardiol 2007;42:S171-S189.
30 Lim SY, Davidson SM, Hausenloy DJ, Yellon DM: Preconditioning and postconditioning: the essential role of the mitochondrial permeability transition pore. Cardiovasc Res 2007;75:530-535

31 Tang XL, Sato H, Tiwari S, Dawn B, Bi Q, Li Q, Shirk G, Bolli R: Cardioprotection by postconditioning in conscious rats is limited to coronary occlusions $<45 \mathrm{~min}$. Am J Physiol Heart Circ Physiol 2006;291:H2308H2317.

32 Zhao Z, Vinten-Johansen J: Postconditioning: reduction of reperfusion-induced injury. Cardiovasc Res 2006;70:200-211.

33 Vuuren DV, Lochner M: Ischaemic postconditioning: from bench to bedside. Cardiovasc J Afr 2008;19:311-320.

34 Yetgin T, Manintveld OC, Duncker DJ, van der Giessen WJ: Postconditioning against ischaemia-reperfusion injury: ready for wide application in patients. Neth Heart J 2010;18: 389-392.

35 Hansen PR, Thibault H, Abdulla J: Postconditioning during primary percutaneous coronary intervention: a review and meta-analysis. Int J Cardiol 2010;144:22-25. 